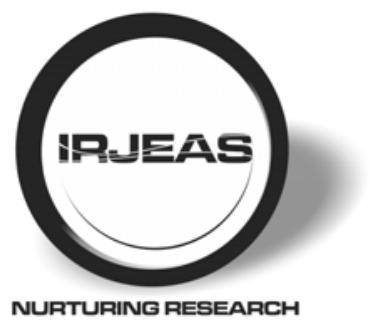

INTERNATIONAL RESEARCH JOURNAL

OF

ENGINEERING \& APPLIED SCIENCES

ISSN: 2322-0821(0)

VOLUME 9 ISSUE 4

ISSN: $2394-9910(\mathrm{P})$

Oct 2021 - Dec 2021

www.irjeas.org

\title{
TWO DIMENSIONAL AEROFOIL WIND TURBINE BLADE DESIGN AND ANALYSIS USING CFD ANALYSIS
}

\author{
*Kamal Bhan Singh ${ }^{1 *}$, Yogesh Mishra ${ }^{2}$ \\ ${ }^{1} M$. Tech Scholar, Department of Information Science \& Technology, NIIST, Bhopal, India \\ ${ }^{2}$ Asct.Professor, Department of Information Science \& Technology, NIIST, Bhopal, India
}

*Corr. Author - kamalkool181@gmail.com DOI - 10.55083/irjeas.2021.v09i04005

\begin{abstract}
In the current scenario, wind turbine energy accounts for $\mathbf{7 0 \%}$ of total renewable energy used in India. The Indian wind energy sector has a capacity of $20 \mathrm{GW}$ installed (as on 31.5.2017). In terms of installed wind power capacity, India ranks fifth in the world and is regarded as a major player in the global wind energy market. For the current work, a design method based on modelling in Uni-graphics and followed by simulation using the CFD (Computational Fluid Dynamics) star $\mathrm{ccm}+$ programme is chosen, so that the expense and time required to find the optimum aerodynamic design of a wind turbine blade by experiment can be minimised. The wind turbine aerodynamic theory is used in the analysis. This simulation analyses the characteristics of aerofoils by using star ccm + twodimension models of wind turbine blades. The SST Kturbulent model is used to analyse two-dimensional aero foils NREL S807 and NREL-S809. The dimensionless lift, drag, and pitching moment coefficients of wind turbine blades at various angles of attack were calculated.Two different aero foils, NRELS807 and NREL S809, with ten different angle of attack are also analysed, for a total of 20 cases with a wind speed of $20 \mathrm{~m} / \mathrm{sec}$. Uni-graphics is used for modelling. The firstaero foil NREL S807 has a maximum lift coefficient of 1.25 at a 120 angle of attack and a maximum drag coefficient of 0.134 at a 160 angle of attack. Maximum lift for aero foil $\mathbf{5 8 0 9}$ is 1.15 at an angle of attack (AOA) of 16o, and maximum drag is around 0.176 .
\end{abstract}

Keywords - Aerofoil, CFD, CATIA, Design, Wind Turbine

\section{INTRODUCTION}

According to the World Wind Energy Association, there are over $238,351 \mathrm{MW}$ of wind power capacity in the world as of the end of 2013. (2013 World Wind Energy Report) According to the same wind power advocacy group, wind power now has the capacity to generate $500 \mathrm{TWh}$ per year, which equates to about $3 \%$ of global electricity usage. Wind energy statistics show that it isalready the most important renewable energy source in the world, and that demand for wind energy solutions is increasing. This project includes a discussion of the most important parameters in wind turbine blade design in order to maximize aero foil efficiency. Two different airfoils are compared to see which produces the most efficient wind turbine blade.

\section{OBJECTIVE}

Wind energy allows you to harness the kinetic energy of the wind and use it to generate electricity through rotating machines (wind turbines). Since there has been an interest in generating electricity with wind turbines, several different types of machines have been developed. Wind energy has the potential to be a future source of energy. The horizontal axis wind turbine is currently the machine most commonly used for harvesting wind energy in the field of application (HAWT). The main issue is lowering the cost of wind turbines so that they can compete with traditional energy sources. Methods for improving wind turbine performance and increasing wind turbine power output must be considered. Wind turbine blade design, including blade shape, aerodynamic modification, and structural design method, is an important tool for increasing wind energy power capacity.

In general, an airfoil's lift is primarily determined by its angle of attack and shape. When the incident angle changes, the aerofoil changes direction at a suitable angle, the airfoil deflects the incident air, and the pressure difference changes. This is referred to as aerodynamic force.

Force and can be broken down into two parts: Lift and drag are forces that are used to overcome gravity and are defined as being perpendicular to the direction of the oncoming airflow. It is responsiblefor creating an unequal pressure difference on the upper and lower airfoil surfaces. Force is used to reduce gravity, and the 
higher the lift, the more mass that can be lifted off the ground. The lift to drag ratio of an aero foil should be as high as possible. As a result, when a wind turbine generates electricity, it can improve efficiency. The coefficients of lift and drag, CL and CD, are defined as follows

\section{LIFT COEFFICIENT- \\ $\mathrm{CL}=\mathrm{FL} / .5^{*} \rho \mathrm{v} 2 \mathrm{C}$ \\ DRAG COEFFICIENT- \\ $\mathrm{CD}=\mathrm{FD} / .5^{*} \rho \mathrm{v} 2 \mathrm{C}$}

Where,

$\rho=$ Density of the air

$\mathrm{C}=$ The length of the aero foil, often denoted by the chord

$\mathrm{V}=$ The velocity of air

$\mathrm{FL}=$ Forces acting on aero foil unit for the lift in equations $(\mathrm{N} / \mathrm{m})$.

$\mathrm{FD}=$ Forces acting on aero foil unit for the drag in equations $(\mathrm{N} / \mathrm{m})$.

\section{INDIAN WIND ENERGY STATUS}

Wind power program began in India at the end of fivesixths of the annual plans for 1983-1984 and in recent years has increased dramatically. The main objective of the program was tocommercialize the production of wind energy, support for research and development, provide assistance to wind projects and awareness. Under this program, the Ministry of Non-Renewable Energy (MNRE) has made several changes regarding incentives, plans and policies for wind power. Twenty years have passed since the shape of the world's first offshore wind power Vindeby (5 MW), was built in Denmark. Today, 4,620 MW of offshore wind power was installed worldwide, accounting for approximately $2 \%$ of the total installed capacity of wind power. Over $90 \%$ of it is installed outside Northern Europe, in the North, Baltic and Irish Seas and the English Channel. Most of the rest is in two demonstration projects on the east coast of China. However, there are also high for greater deployment expectations elsewhere, governments and businesses in Japan, Korea, USA, Canada, Taiwan and even India have shown enthusiasm for offshore development in its waters. India is a newcomer to the wind industry compared with Denmark or the USA. But the policy support of the Indian wind energy has led India and ranks fifth capacity most installed wind power. The total installed capacity of 19,565 MW was 30 June 2013 [Madhu Singh 5]. And now India is just behind the United States, China, Spain and Germany. The total installed capacity of wind power shows a better performance of India in the field of wind energy. The top five countries of wind energy are China, USA, Germany, Spain and India, which together represent 73 percent of the global wind capacity. The total installed wind power capacity in India reached $17.9 \mathrm{GW}$ in August 2012 the total capacity added in 2012 was around 1700 total installed capacity MW 2013 in India and 2011 is illustrated rapid growth of installation of wind power was measured in the southern and western India. One needs about 350-360 GW of total capacity of power generation has been reported by the Central Electricity Authority in its national plan for electricity (2012), for the year 2022 [6]. Wind potential onshore only has hitherto been used by India. Despite the fact that India has a coastline 7,500 $\mathrm{km}$, we have not yet taken advantage of our offshore wind resources for electricity generation.

Director Wind offshore Committee was established in August 2012 by MNRE, which published a draft national policy Energy Offshore Wind in May 2013 [7] [8]. Figures below show the total global installed capacity at different countries up to 2017.

\section{COUNTRY}

China

USA

Germany

Span

India

UK

Italy

France

Canada

Denmark

Portugal

Sweden

Australia

Brazil $\quad 2,788$

Japan $\quad 2,655$

Rest of the World

Total 296,065

\section{INSTALLED CAPACITY (MW)}

80,824

60,009

32,422

22,907

19,565

9,610

8,415

7,821

6,578

4,578

4,066

\section{MODELING}

Moreover, the flow past a wind turbine blade is threedimensional, particularly in the blade-tip and root region.

For instance, centrifugal and Coriolis forces are experienced by the boundary layer flow, mainly in the inboard, causing a stall-delay effects, by which higher lift is achieved compared to two-dimensional data.

The aerodynamic research for wind turbines has basically contributed to the fast development of modern wind energy, being the exploring techniques rather primitive just a few decades ago.

Most of those techniques are not universally applicable, so that a better physical understanding is needed. 
International Research Journal of Engineering \& Applied Sciences, IRJEAS

www.irjeas.org, ISSN(O): 2322-0821, Volume 9 Issue 4, Oct-Dec 2021, Page 25-27DOI - 10.55083/irjeas.2021.v09i04005

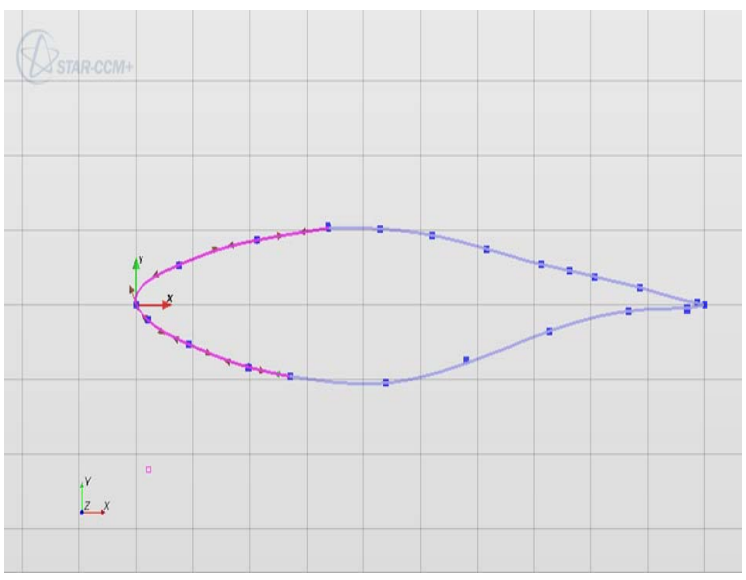

Figure 5.1 S807aero foil designing

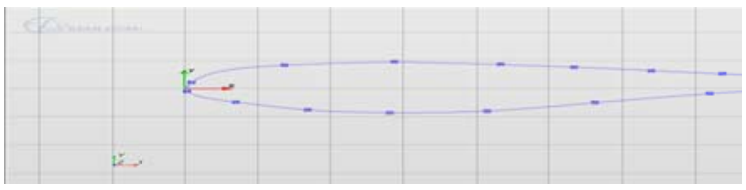

Figure 5.2 S809aero foil designing

\section{RESULTS}

In two-dimensional aero foil modeling, the comparison between the CFD results and experimental data shows star cam + is a reliable benchmark. Velocity of wind taken at $20 \mathrm{~m} / \mathrm{swith}$ Reynolds no of $1 * 106$ is used. Aerodynamic performances of different aero-foils have been compared.

\section{RESULTS FOR AEROFOIL S807}
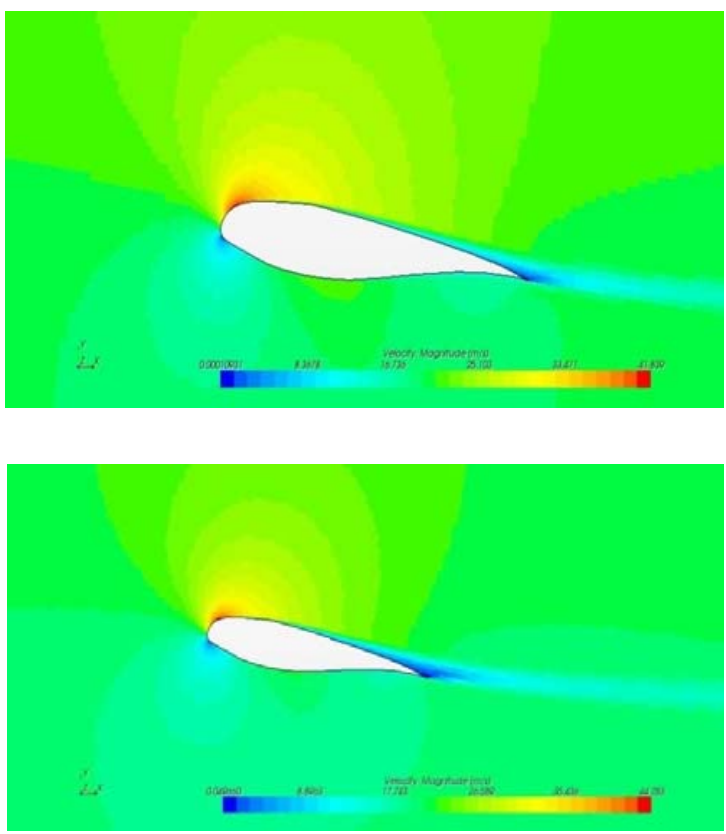

For NREL S807 maximum lift is 1.25 at angles of attack 12 deg.further increasing AOA gives drop in lift and drag is increasing to 0.134.For NREL S809 maximum lift of 1.155 at $16 \mathrm{deg}$. With high drag of 0.176 . The simulated results demonstrate that the s809aero foil has a better aerodynamic performance than the S807aero foil. Star $\mathrm{ccm}+$ provides a better correlation with theoretical data for power output prediction.Link can apply the force of $3000 \mathrm{~N}$.

\section{REFERENCE}

[1] J.L. Tangier NREL Airfoil Families for HA WTs National Renewable EnergyEnergy Laboratory report, AIAA Aerospace Sciences Meeting and Exhibit,volume291,.1984

[2] Mohammad A. Hossain et. Al Numeric Investigation of compressible flow Over NREL Phase VI Airofoils, International Journal of Engineering Research \& Technology (IJERT) vol. 2 Issue2,

February -2011 ISSN : 2278-0181

[3] PeterJ.SchubelandRichardJ.Crossley,WindT urbineBladeDesignEnergies2012,5,3425- 3449; doiL3390/en5093252012.

[4] Mukesh M. Yelmule et. Al CFD predictions of NREL Phase VI Rotor Experiments inNASA Ames Wind tunnel INTERNATIONAL JOURNAL of RENEWABLE ENERGY RESEARCH Vol3. No.2,2013.

[5] Mr. Josua Kirsch, Design, development, manufacturing and Testing of Aerofoil Blades For Small Wind Mill INTERNATIONAL JOURNAL of RENEWABLE ENERGY RESEARCHVOL 2.No.4,2013.

[6] BrentW.Pomeroyet.

al,CFDAnalysisofMultielementAirfoilsforWid $30^{\text {th }}$ AIAAApplied Aerodynamics Conference 20122018 25-25 June 2012, New Orleans,Louisiana.

[7] ChrisKaminkyandAustinFilushusing,ACFDS tudyofWindTurbineAerodynamicsJournal of Fluid Engineering, 124:393-9,2002. 